\title{
Cutaneous Activation of the Inhibitory L30 Interneurons Provides a Mechanism for Regulating Adaptive Gain Control in the Siphon Withdrawal Reflex of Aplysia
}

\author{
Thomas M. Fischer ${ }^{1}$ and Thomas J. Carew ${ }^{1,2}$ \\ Departments of ${ }^{1}$ Psychology and ${ }^{2}$ Biology, Yale University, New Haven, Connecticut 06520
}

The functional role of inhibition in the neural network underlying the siphon withdrawal response (SWR) of Aplysia was assessed by examining a recurrent circuit comprised of identified inhibitory interneurons (L30s), and excitatory interneurons (L29s). We previously showed that activity-dependent potentiation of the L30 inhibitory synapse onto L29 can regulate the net excitatory input elicited by tactile siphon stimulation onto siphon motor neurons (LFS cells) (Fischer and Carew, 1993a). To explore the functional significance of L30 potentiated inhibition, we have examined how a behaviorally relevant stimulus that activates the $L 30$ interneurons modulates the SWR circuit.

Utilizing a reduced preparation, we show that weak tactile stimulation of the tail strongly activates the L30s, and leads to significant potentiation of the L30 synapse. Next, we demonstrate that similar weak tail stimulation produces significant inhibition of siphon tap-evoked responses in both L29 interneurons and LFS motor neurons. We further show that this form of inhibition is transient, having a time course of approximately $60 \mathrm{sec}$. Finally, we directly tested the role of the L30s in mediating this form of inhibition by hyperpolarizing two (of three) L30 interneurons during tail stimulation. L30 inactivation significantly attenuated tail stimulation-induced inhibition of siphon-evoked input to both L29 interneurons and LFS motor neurons. Based on these results, we suggest that L30-potentiated inhibition may have an important adaptive role in optimizing the signal-to-noise ratio for activation of the SWR circuit by providing stabilization of SWR responsiveness under a wide range of environmental conditions.

[Key words: interneuron, neuronal network, synaptic plasticity, signal- to-noise ratio, reflex, posttetanic potentiation]

An important function of plasticity in the nervous system is to enable an organism to adapt to a changeable environment. Such adaptive plasticity often involves multiple alterations of excitatory and inhibitory processes throughout a neural network

\footnotetext{
Received Mar. 24, 1994; revised June 28, 1994; accepted July 13, 1994.

We thank D. Blazis, M. Stopfer, and W. Wright for valuable comments on an earlier version of the manuscript. This work was supported by PHS Grant F32MH10334-01 to T.M.F., and NSF Grant BNS831 1300, NIH Grant KO1-MH-141083, and AFOSR Award AF 89-0362 to T.J.C.

Correspondence should be addressed to Thomas J. Carew, Yale University Department of Psychology, P.O. Box 208205, New Haven, CT 06520-8205.

Copyright (C) 1995 Society for Neuroscience $0270-6474 / 95 / 150762-12 \$ 05.00 / 0$
}

(Getting, 1989; Harris-Warrick and Marder, 1991; Korn et al., 1992; Wu et al., 1993; Kirkwood and Bear, 1994). Altering the balance between excitation and inhibition in a neural circuit can profoundly affect its function, yet in complex circuits it is often difficult to relate modifications of these processes to changes in the functional output of a circuit. The siphon withdrawal response (SWR) of the marine mollusc Aplysia californica provides a preparation in which it is possible to examine interactions between excitatory and inhibitory processes at a cellular level within a defined neural circuit. The cellular analysis of SWR plasticity has focused extensively upon excitatory processes. For example, behavioral sensitization of the SWR has been shown to be accompanied by facilitatory modifications at several loci within the SWR circuit, including sensory neurons (for reviews, see Byrne et al., 1993; Hawkins et al., 1993), interneurons (Frost et al., 1988; Trudeau and Castellucci, 1992), and motor neurons (Frost et al., 1988; Hickie et al., 1993). However, inhibitory processes have also been identified as important components of SWR regulation (Krontiris-Litowitz et al., 1987; Mackey et al., 1987; Marcus et al., 1988; Rankin and Carew, 1989; Wright et al., 1991; Illich et al., 1994). For example, rcduction of inhibitory processes have been implicated as a significant component of SWR sensitization (Frost et al., 1988; Trudeau and Castellucci, 1993).

We have recently examined how dynamic interactions between excitatory and inhibitory interneurons contribute to SWR function and plasticity (Blazis et al., 1993; Fischer and Carew, 1993a). We have focused upon a recurrent circuit formed by the L29 excitatory interneurons and the L30 inhibitory neurons (Hawkins et al., 1981a). L29 interneurons provide substantial excitatory input to siphon motor neurons; they also activate the L30s, which provide recurrent inhibitory feedback onto the L29s (Hawkins et al., 1981 a; Frost, 1987; Fischer and Carew, 1993a). An intriguing feature of L30 inhibitory synaptic output is that it exhibits pronounced activity-dependent potentiation. For example, activation of the L29s can produce sufficient activity in the L30s to potentiate the L30 IPSP back onto the L29s, which inhibits subsequent L29 responses when the L29s and L30s are coactivated, thereby decreasing $\mathrm{L} 29 \mathrm{~s}$ input to siphon motor neurons. The recurrent interactions between L29 and L30 interneurons thus provide a mechanism for activity-dependent regulation of excitatory input to siphon motor neurons (Fischer and Carew, 1993a).

Our identification of the dynamic network interactions described above raised the important issue of the functional significance of the L29/L30 circuit. To extend our previous results 
and address this issue, we have focused on three general questions. First, what kind of behaviorally relevant stimuli activate the circuit? Second, how does such activation modulate siphon responding? Third, can the inhibitory $\mathrm{L} 30$ elements be causally related to response modulation? We found that weak tactile stimulation of the tail readily activates and potentiates synaptic transmission from the L 30 interneurons; this same stimulus also produces significant inhibition of siphon-evoked responses in both siphon motor neurons and L29 interneurons. We further found that the time course of the inhibition corresponds closely to the time course of $\mathrm{L} 30$ potentiated inhibition produced by direct activation of L30 (Fischer and Carew, 1993a). Finally, we directly tested the role of the L30s in mediating the inhibitory process by inactivating them during tail stimulation. L30 inactivation significantly attenuated the inhibition of siphonevoked responses in both siphon motor neurons and L29 interneurons. These results lead us to propose an adaptive role for L30-mediated low threshold inhibition in stabilizing SWR responsiveness under conditions of different levels of ambient environmental stimulation.

Some of the results in this article have been presented in abstract form (Fischer and Carew, 1993b).

\section{Materials and Methods}

Animals. Adult Aplysia californica (100-300 gm) were obtained commercially (Marinus Inc., Long Beach, CA) and maintained at $15^{\circ} \mathrm{C}$ in a 600 liter aquarium containing continuously circulating, aerated Instant Ocean (Aquarium Systems, Mentor, $\mathrm{OH}$ ). Animals were housed in groups of up to six, and fed dried seaweed weekly.

Experimental preparation. An isolated mantle/tail preparation was used in our experiments (Fig. 1). Animals were first anesthetized by injection of isotonic $\mathrm{MgCl}_{2}$ into the body cavity. The central nervous system (abdominal and ring ganglia) mantle organs (siphon, gill, and mantle shelf), and the tail were then removed from the animal; all peripheral nerves except the siphon nerve and the P9 (tail) nerves were cut. The preparation was then transferred to a Sylgard (Dow-Corning) coated recording dish containing $50 \% \mathrm{MgCl}_{2} / 50 \%$ artificial sea water (ASW: $460 \mathrm{~mm} \mathrm{NaCl}, 55 \mathrm{~mm} \mathrm{MgCl}, 11 \mathrm{mM} \mathrm{CaCl}_{2}, 10 \mathrm{~mm} \mathrm{KCl}, 10$ mM Tris, $\mathrm{pH}$ 7.4) and pinned with the tail and mantle dorsal side up and the siphon unobstructed. The abdominal ganglion was pinned ventral side up on a recording platform, and the left hemiganglion was surgically desheathed. The siphon artery and the tail were cannulated, and the preparation was continuously perfused with cool ASW (16$18^{\circ} \mathrm{C}$ ) throughout the experiment. At least $1 \mathrm{hr}$ of postdissection recovery time was allowed prior to physiological recordings, after which evoked contractions of the siphon and gill could readily be elicited by tactile stimulation of the siphon or the tail.

Standard intracellular recording techniques were used. Neurons were impaled with glass microelectrodes (resistance 10-15 M $\Omega$ ) containing either $3 \mathrm{~m} \mathrm{KCl}, 3 \mathrm{~m} \mathrm{KAc}$, or $0.6 \mathrm{M} \mathrm{K}_{2} \mathrm{SO}_{4} \cdot 20 \mathrm{~mm} \mathrm{KCl}$. Electrical potentials were amplified on Getting 5-A (Getting Instruments, Iowa City, IA) or Axoclamp 2-A (Axon Instruments, Burlington, CA) amplifiers, and then digitized (Medical Systems Corp., Greenvale, NY) for tape storage and computer analysis.

Experimental procedures and quantitative measures. Experiments were designed to examine how weak tactile stimulation of the tail modifies the circuit underlying siphon withdrawal, using tactile stimulation of the siphon to activate the SWR. The tail was stimulated gently and continuously with a soft bristled paint brush (\#6 camel hair) for a $5 \mathrm{sec}$ period (Fig. 1). Input to the SWR circuit was then evoked by brief, 60 msec taps to the siphon, using a glass probc attached to a stimulatordriven electrical relay (Fischer and Carew, 1993a). Since tail stimulation usually produced movement of the siphon, the siphon stimulus was centered near the base of the outer surface of the siphon, where such movements were minimal. Activity in the SWR circuit was monitored as polysynaptic (complex) EPSPs in identified LFS siphon motor neurons (hyperpolarized $50 \mathrm{mV}$ below rest to prevent action potentials), or in L29 excitatory interneurons. LFS motor neurons could be uniquely

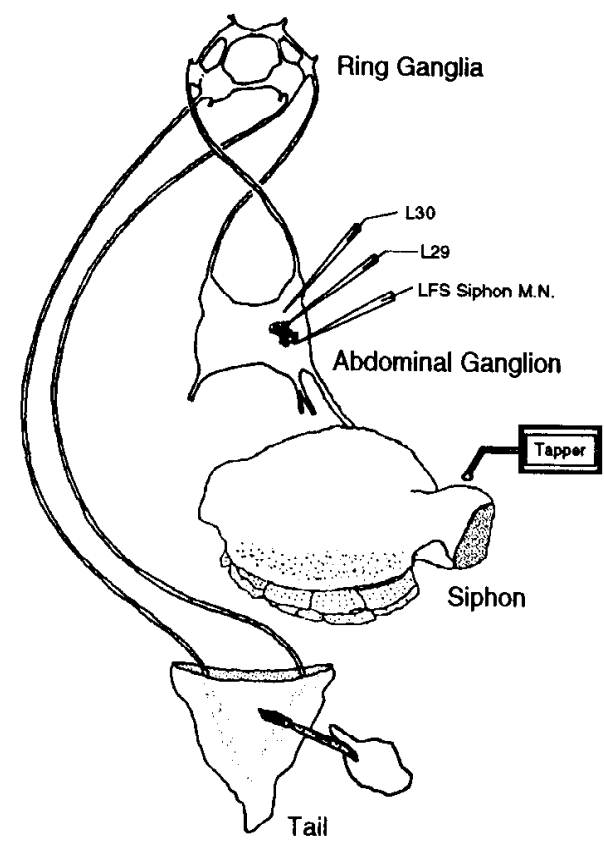

Figure 1. Experimental preparation. Weak tactile stimulation of the tail was used to induce inhibition in the SWR neural circuit, which was activated by a brief mechanical tap to the siphon (see Materials and Methods).

identified by visually monitoring siphon movements induced by intracellular activation of the motor neurons, since they produce characteristic movements which are either directed anteriorly (LFS-A cells) or posteriorly (LFS-B cells) (Frost et al., 1988; Hickie and Walters, 1990). L29 interneurons were identified on the basis of size and position, their ability to recruit recurrent IPSPs when intracellularly activated, and their characteristic cellular response to the siphon tap stimulus (Hawkins et al., 1981a; Fischer and Carew, 1993a). L30 interneurons were identified on the basis of their recurrent synaptic relationship with L29: L30 interneurons are excited by L29 activation and in turn produce IPSPs back onto L29 (Hawkins et al., 1981a; Fischer and Carew, 1993a).

The following general experimental procedure was employed. A total of three tactile stimuli were delivered to the siphon: a baseline trial, followed by a test trial, then a recovery trial. Prior to the test trial, the tail was stimulated for $5 \mathrm{sec}$. The timing of tail stimulation was set so the cessation of stimulation preceded the test trial by intervals of 0 (immediate), 20,40 , or $60 \mathrm{sec}$. The $20 \mathrm{sec}$ interval was used in most experiments; other intervals were used to assess the time course of SWR circuit modulation produced by tail stimulation. In experiments in which time course data wcre obtaincd, a 2 min ISI for siphon stimulation was used. This short ISI enabled us to repeatedly examine the same neuron at different test intervals. The ordering of test intervals were randomly varied for each neuron examined. A rest period of 5-10 min was typically allowed between the individual experiments.

As a quantitative measure of excitatory input to LFS motor neurons, the area underneath the initial $500 \mathrm{msec}$ of the complex EPSP in the motor neuron evoked by siphon tap (the approximate duration of the synaptic response to the $60 \mathrm{msec}$ tap) was integrated (in $\mathrm{mV} \cdot \mathrm{msec}$ ) using a Macintosh-based physiological analysis software package (MACLAB; ADInstruments, Milford, MA). This measure has the advantage in that it is sensitive to changes of both the amplitude and duration of the motor neuron complex EPSP. Test and recovery responses were expressed as a percentage of the baseline trial, so that scores of $0 \%$ signify no change in the response compared to baseline. L29 responses evoked by siphon tap were quantified by counting the total number of L29 spikes within a $500 \mathrm{msec}$ period following the first evoked spike. Test and recovery responses were expressed as difference scores from baseline responses.

All summary data are presented as means \pm SEM. Statistical analysis was carried out using $t$ tests for repeated measures; all probability values reported are two tailed. 


\section{A. AT REST}
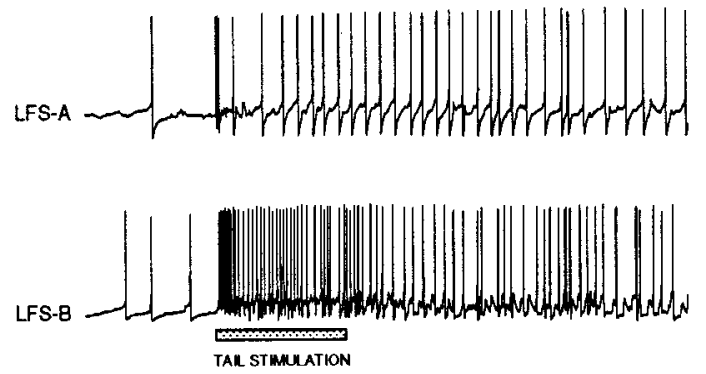

B. HYPERPOLARIZED
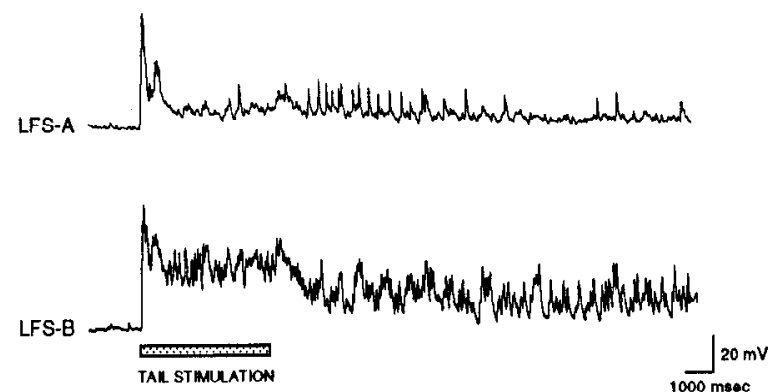

Figure 2. Weak tactile stimulation of the tail elicits different responses in LFS- $\Lambda$ and LFS-B siphon motor neurons. Simultaneous recordings from identified LFS-A and LFS-B motor neurons (see Materials and Methods). $A$, Tactile stimulation of the tail (stippled bar) evokes robust firing of LFS-B motor neurons, but only weak firing in LFS-A cells. $B$, Hyperpolarization of these same LFS motor neurons during tail stimulation reveals strong synaptic input onto LFS-B cells, but only weak and brief input onto LFS-A cells.

\section{Results}

Weak tactile stimulation of the tail activates elements in the siphon withdrawal network

Stimulation of the tail produces a variety of responses in abdominal ganglion neurons that are involved in defensive withdrawal of the gill and siphon (Frost et al., 1988; Hawkins and Schacher, 1989; Fang and Clark, 1990; Hickie and Walters, 1990; Wright et al., 1991; Fang and Clark, 1992, 1993). Of primary interest in the present experiments are the responses that tail stimulation evokes in the LFS siphon motor neurons, the L29 excitatory interneurons, and the L30 inhibitory interneurons. Our present observations, coupled with work by other investigators (Frost et al., 1988; Hawkins and Schacher, 1989), indicate that subtypes of both LFS and L29 neurons can be readily identified based in part upon differential responses to the tail stimulation. This is not the case for L30 neurons, which appear homogeneous in their response properties.

LFS motor neurons have been divided into two subtypes based upon the direction of siphon movement they produce: the LFS-A type (approximately three in number; Hickie and Walters, 1990) bend the siphon towards the head; the LFS-B type (approximately five in number; Hickie and Walters, 1990) bend the siphon towards the tail (Frost et al., 1988; Hickie and Walters, 1990). These two types of motor neurons also respond differentially to electric shock of the tail (Frost et al., 1988; Fang and Clark, 1992, 1993; Hickie et al., 1993). We obtained similar results in a number of preparations examining the response of LFS motor neurons to weak tactile stimulation of the tail (see Materials and Methods). These results are illustrated in Figure
A. L29 - STIMULATE TAIL

L29-A

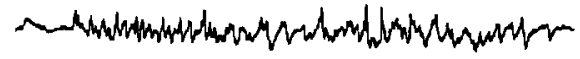

L29-B

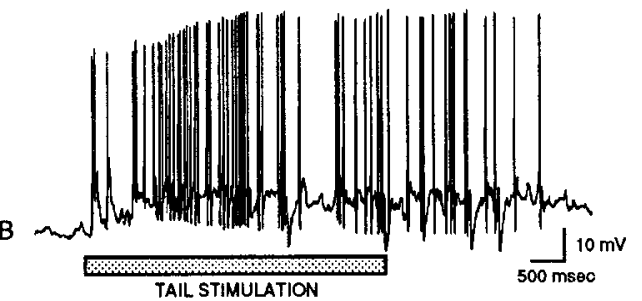

\section{B. L29 - TAP SIPHON}

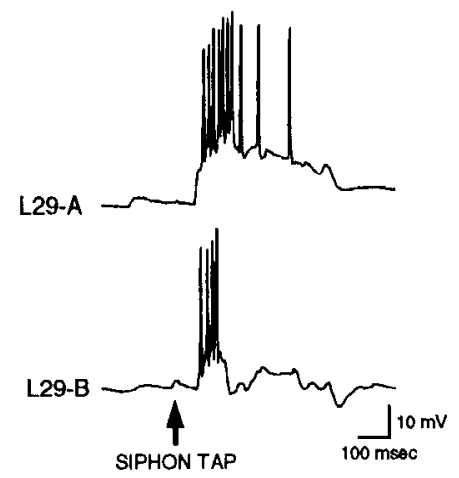

Figure 3. L29 interncuron subtypes can be distinguished by their distinct responses to cutaneous tail or siphon stimulation. $A$, Simultaneous recordings from two identified L29 interneutons (see Materials and Methods). Tail stimulation (stippled bar) evokes robust firing in the L29-B cell; the L29-A cell does not fire to this stimulus. B, A recording from the same cells depicted in Part 1 , demonstrating that siphon tap (arrow) elicits more action potentials and a longer-lasting depolarization in L29-A cells than in L29-B cells.

2, which shows simultaneous recordings from both an LFS-A and an LFS-B motor neuron during tail stimulation. LFS-B cells exhibit a prolonged increase in firing which typically outlasts the duration of stimulation (Fig. $2 A$ ); hyperpolarization reveals an underlying persistent increase in synaptic input (Fig. $2 B$ ). In contrast, LFS-A cells exhibit a briefer and less intense burst of activity to tail stimulation (Fig. $2 A$ ); hyperpolarization reveals a transient increase in synaptic input (Fig. $2 B$ ). The observed difference in tail stimulation-evoked input to LFS motor neurons was an important consideration for selecting motor neurons for our studies; the increase in background synaptic input onto the LFS-B cells following tail stimulation could easily confound measures of siphon tap-evoked input to these neurons, since there was an increased likelihood that siphon-evoked input would coincide with the ongoing tail stimulus-evoked input. Thus, in our experiments we primarily focus upon the LFS-A siphon motor neurons.

The L29 interncurons (approximately five in number; Hawkins et al., 1981a) have previously been divided into two subtypes based upon qualitative differences observed in tactile receptive fields: one type responds relatively equally to siphon shock or tail shock (L29-A cells), whereas the other responds preferentially to tail shock (L29-B cells; Hawkins and Schacher, 1989). This difference between subtypes of L 29 neurons is perhaps more apparent when comparing siphon and tail-evoked responses using weak tactile stimuli. As demonstrated in Figure 


\section{A. L30 - WEAK TAIL STIMULATION}

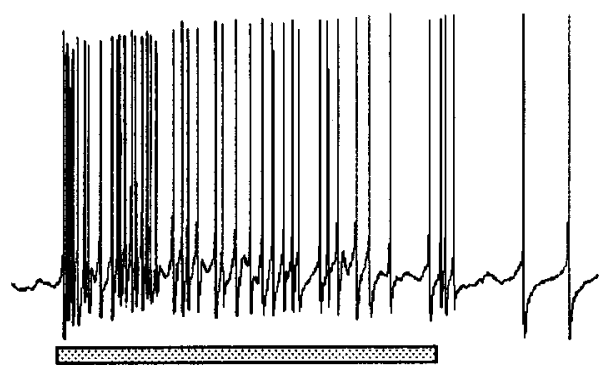

WEAK TAIL STIMULATION

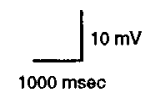

\section{B. L3O - NOXIOUS TAIL SHOCK}

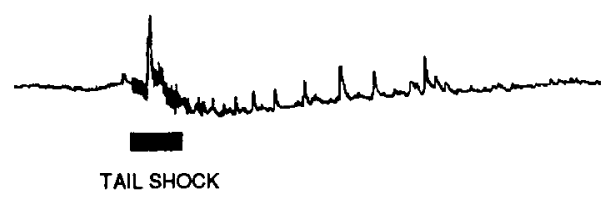

Figure 4. Weak and noxious tail stimulation elicit opposite responses in L30 interneurons. $A$, Rccording from an identified L30 interneuron (see Materials and Methods). Weak cutaneous tail stimulation (stippled bar), using a soft-bristled brush, evokes robust firing in L30 neurons. $B, A$ recording from the same cell in Part 1 . Noxious tail shock (solid bar; $30 \mathrm{~mA} \mathrm{AC}$ for $1 \mathrm{sec}$ ) produces a slow inhibitory response in L30.

$3 A$, L29-B cells respond briskly to tail stimulation. In contrast, L29-A cells tend to firc cither wcakly or not at all to the stimulation. Instead, IPSPs are often evoked in L29A cells by tail stimulation. L29-A and L29-B type neurons also exhibit clear qualitative differences to siphon stimulation (Fig. 3B): L29-A cells typically fire a greater number of spikes and show a longer lasting depolarization to the siphon tap than L29-B cells. As with the LFS cells, these differences between L29 cells were important considerations in our experiments. We chose to primarily examine the L29-A cells for two reasons: the larger number of spikes to our "test" stimulus (siphon tap) provides a greater dynamic range of measurement; and the lack of maintained firing following tail stimulation ensures that siphon tapevoked measures were not confounded by ongoing tail-evoked activity.

In contrast to the LFS and L29 neurons, the L30 interneurons (approximately three in number; Hawkins et al., 1981a) appear to be homogeneous in their response characteristics to weak tail stimulation. All L30 neurons examined were activated by the tail stimulus, firing at an average rate of $7.3 \pm 0.7 \mathrm{~Hz}$ over a 5 sec stimulation period $(N=8)$. The L30s often maintained their firing for a short period following termination of the stimulus (Fig. 4A; also see Fig. 8). These neurons also respond to stimulation of the siphon, firing two to five spikes to the brief siphon tap used in these experiments (Fischer and Carew, 1993a). In contrast to their responses to weak tactile stimulation, L30 interneurons are inhibited following noxious tail shock (Fig. $4 B$ ). Thus L30 interneurons appear to be preferentially activated by non-noxious tactile stimuli.

Since weak tail stimulation produced strong activation of the L30s, and since intracellular activation of L30 leads to significant potentiation of synaptic transmission from L30 (Fischer and Carew, 1993a), we would expect that activation from tail

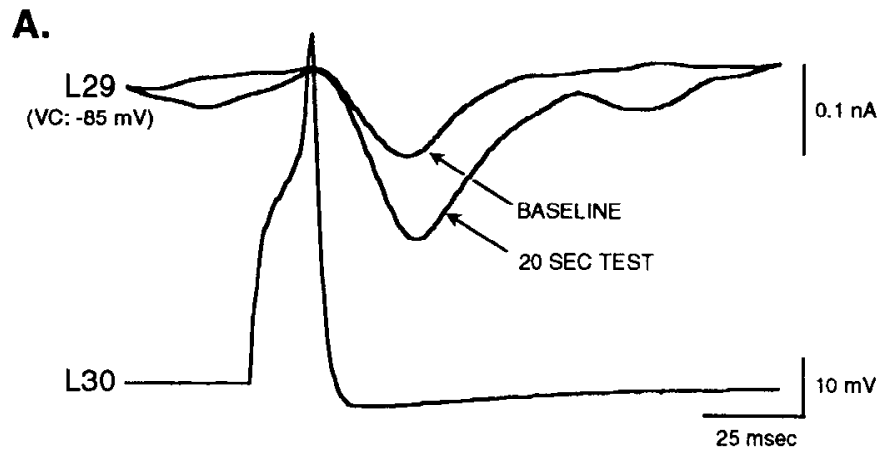

B.

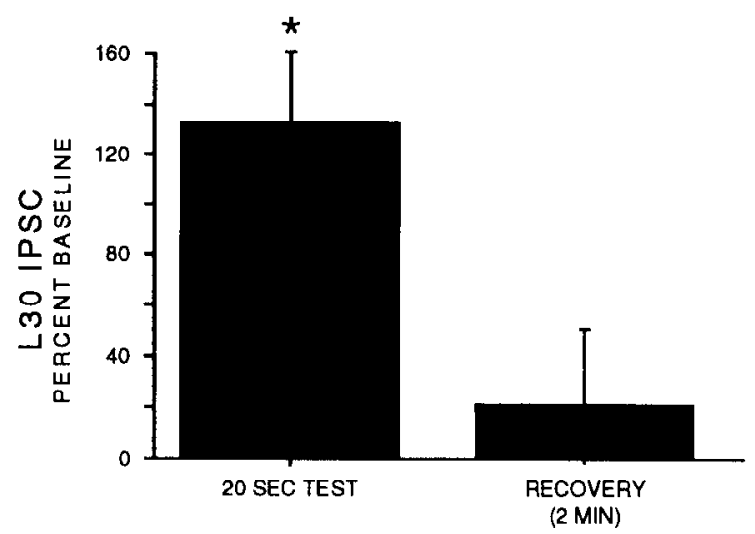

Figure 5. The L30 inhibitory synapse is potentiated following weak tail stimulation. $A$, Simultaneous intracellular recordings from identified L29 and L30 interneurons. The L30 synapse onto L29 was examined by generating a single action potential in L30 at a $2 \mathrm{~min}$ ISI (only one is shown). L29 was placed under two electrode voltage clamp at a holding potential of $-85 \mathrm{mV}$. This inverts the inhibitory postsynaptic current (IPSC) so that the IPSC is seen as inward current. Evoked inhibitory currents in L29 are shown superimposed. Following a baseline IPSC (BASELINE), the tail was stimulated for $5 \mathrm{sec}$. Twenty seconds following tail stimulation, the size of the IPSC is substantially enhanced (20 $S E C T E S T$ ). B, Summary of five experiments examining tail-induced potentiation of the $L 30$ synapse. L30 IPSCs are expressed as a percentage of baseline, so that scores of $0 \%$ indicate no change. Twenty seconds following tail stimulation (20 SEC TEST), the L30 IPSC is significantly enhanced. RECOVER $Y$ trials 2 min later were not significantly different from baseline. $\left(^{*}, p<0.05\right.$; compared to baseline).

stimulation would also potentiate the L30 inhibitory synapse. We carried out a series of experiments to test this prediction, examining the L30 synapse onto identified L29 interneurons. In these experiments, L29 neurons were impaled with two microelectrodes and voltage clamped at holding potentials ranging from -75 to $-90 \mathrm{mV}$. At these holding potentials, the L30 inhibitory postsynaptic current (IPSC) appears as inward current (the reversal potential of the L30 IPSC is approximately -55 $\mathrm{mV}$ ). The magnitude of the L30 IPSC was examined at 2 min intervals by eliciting a single action potential in L30. Following a basclinc IPSC mcasurcment, the tail was stimulated for $5 \mathrm{scc}$ (see Materials and Methods and Fig. 1); the L30 IPSC was examined $20 \mathrm{sec}$ later. As shown in Figure $5 \mathrm{~A}$, tail-induced activation of L30 significantly increased the amplitude of the L30 IPSC onto L29, in this case by $183 \%$ over baseline. A summary of five such experiments is shown in Figure $5 B$, which demonstrates significant potentiation of the L30 IPSC following tail stimulation $\left(20 \mathrm{sec}\right.$ test: mean diff. $=133 \pm 28 \%, t_{4}=3.05$, $p<0.01$ ); 2 min recovery trials were not significantly different 
Figure 6. Weak tail stimulation inhibits siphon tap-evoked responses of L29-A interneurons. $A$, Recording from an identified L29-A cell. Following one baseline trial $(0: 00 \mathrm{MIN})$, the tail was stimulated for $5 \sec (1: 35 \mathrm{MIN}$, stippled bar). Twenty seconds following tail stimulation (test trial, 2:00 MIN), the number of L29-A spikes is reduced. The response recovers to baseline levels 2 min later (recovery trial, 4:00 MIN). $B$, Summary of experiments examining the time course of this form of inhibition. L29-A responses were tested either immediately after, or 20,40 , or $60 \mathrm{sec}$ following tail stimulation. The data are expressed as a mean difference score \pm SEM from their respective baseline measures. Significant inhibition was found at all test intervals. $\left({ }^{* *}, p<0.01\right.$; ${ }^{*}, p<0.05$; compared to baseline).

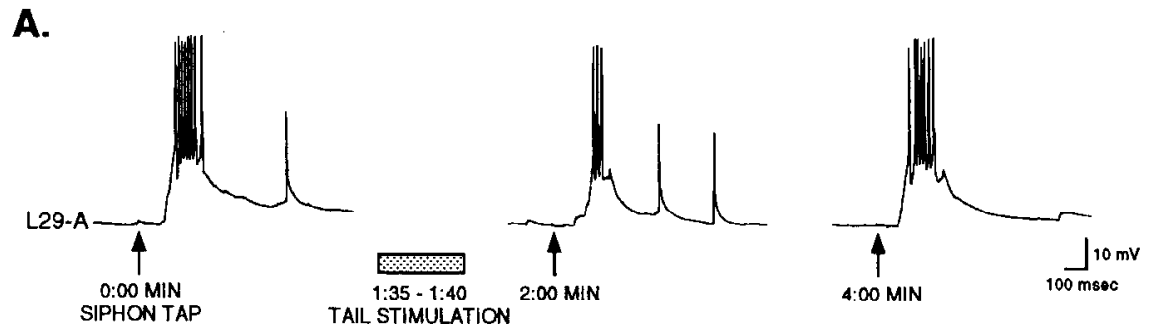

B.

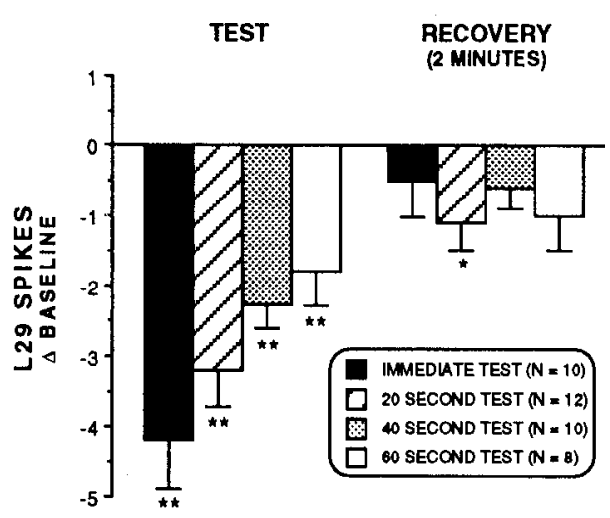

from baseline (mean diff. $=21 \pm 29 \%, t_{4}=0.73, p=0.50$ ). Thus, activation of $\mathrm{L} 30$ by weak tactile stimulation of the tail produces a significant potentiation of the L30 inhibitory synapse.

\section{Weak tail stimulation produces inhibition of siphon-evoked responses in L29 interneurons and LFS motor neurons}

1. L29 interneurons. Strong electrical shock to the tail has often been used in experiments examining modulation of the SWR (Carew et al., 1981; Mackey et al., 1987; Erickson and Walters, 1988; Marcus et al., 1988; Hawkins et al., 1989; Walters, 1989; Wright et al., 1991; Illich et al., 1994). In the present experiments, we were interested in examining how non-noxious, weak tactile stimulation of the tail modifies the SWR circuit, especially in light of the observed potentiation of L30 inhibition by such stimulation (Fig. 5). In these experiments, we have separately focused upon the L29-A type interneurons and LFS-A siphon motor neurons. Input to the SWR circuit was cvoked by tapping the siphon at a $2 \mathrm{~min}$ ISI. Three siphon stimuli were given: a baseline stimulus, a test stimulus, and a recovery stimulus. Prior to the test stimulus, the tail was stimulated for $5 \mathrm{sec}$; the interval between the cessation of tail stimulation and the test stimulus was systematically varied (see Materials and Methods; test intervals of $20 \mathrm{sec}$ are commonly shown in subsequent examples of experimental results). Results from a typical experiment examining L29-A interneurons are shown in Figure $6 \mathrm{~A}$. Twenty sec following tail stimulation (shaded bar), the number of siphon tap-evoked spikes in L29-A is markedly reduced, compared to baseline. The L29-A responsiveness recovers 2 min later. Comparable results were obtained in 12 experiments (summarized in Fig. 6B), which showed that the number of tapevoked L29-A spikes was significantly reduced $20 \mathrm{sec}$ following tail stimulation (mean diff. $=-3.2 \pm 0.5$ spikes, $t_{11}=6.09, p$ $<0.001$ ). Recovery measures for $20 \mathrm{sec}$ tests were still significantly reduced compared to baseline measures (mean diff. $=$
$-1.1 \pm 0.4$ spikes, $t_{11}=2.86, p<0.05$ ); however, these measures were significantly greater than test values (mean diff. $=$ $2.1 \pm 0.4$ spikes, $t_{11}=5.50, p<0.001$ ), indicating that significant recovery had occurred 2 min after tail stimulation.

We next carried out a series of experiments to determine the time course of the inhibition of L29-A interneurons produced by tail stimulation (Fig. 6B). In these experiments, we often examined the same neuron at different test intervals, allowing a rest period of 5-10 min between experiments (see Materials and Methods). We observed a significant reduction in the number of tap-evoked L29-A spikes following tail stimulation at all test intervals; inhibition was greatest immediately following tail stimulation, and was progressively smaller at 20,40 , or $60 \mathrm{sec}$ test intervals (immed: mean diff. $=-4.2 \pm 0.6$ spikes, $t_{9}=6.50$, $p<0.001 ; 20 \mathrm{sec}$ : given above; $40 \mathrm{sec}$ : mean diff. $=-2.3 \pm$ 0.3 spikes, $t_{9}=8.83, p<0.001 ; 60 \mathrm{sec}$ : mean diff. $=-1.8 \pm$ 0.5 spikes, $t_{7}=3.33, p<0.01$ ). Measures in the $2 \mathrm{~min}$ recovery trials for the immediate, 40 , and $60 \mathrm{sec}$ tests were not significantly different from baseline (immed: mean diff. $=-0.5 \pm 0.5$ spikes, $t_{9}=1.10, p=0.30 ; 40$ sec: mean diff. $=-0.6 \pm 0.3$ spikes, $t_{9}=1.77, p=0.11 ; 60 \mathrm{sec}$ : mean diff. $=-1.0 \pm 0.5$ spikes, $t_{7}=1.87, p=0.10$ ). These data demonstrate that weak tactile stimulation of the tail produces transient inhibition of siphon tap-evoked L29-A responses, with a time course of at least 60 sec.

In the above experiments, we focused on the L29-A type interneurons, in which a weak tail stimulus induced clear inhibition of siphon-evoked responses. This observation left open the important question of whether the tail-induced inhibitory process was expressed uniquely in the L29-A cells, or was expressed throughout the $\mathrm{L} 29$ interneuronal pool. To address this question, we carried out another series of experiments $(N=7)$ examining the effects of weak tail stimulation on the siphonevoked responses of the L29-B cells (data not shown). Twenty seconds following the cessation of tail stimulation, siphon-tap 


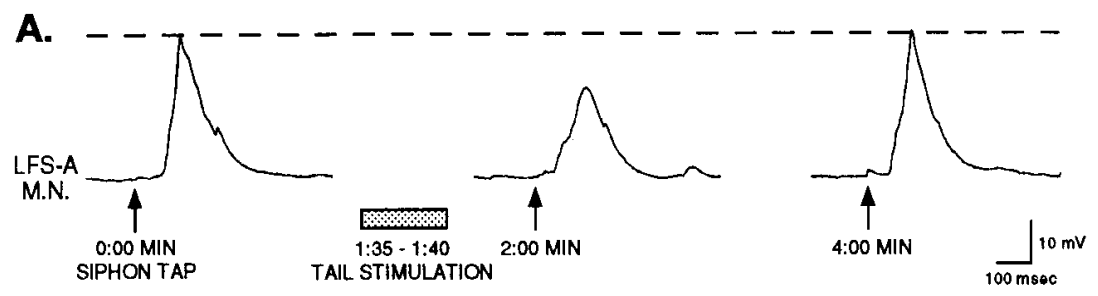

B.

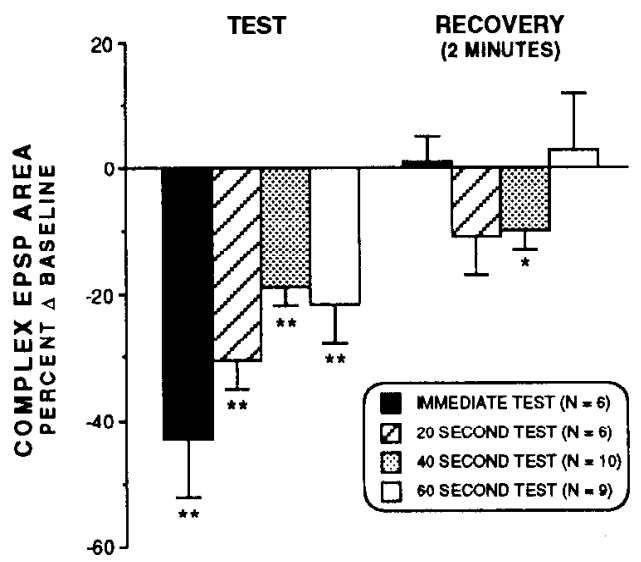

Figure 7. Weak tail stimulation inhibits siphon-evoked complex EPSPs in LFS-A siphon motor neurons. $A$, Recording from an identified LFS-A motor neuron (hyperpolarized to prevent action potentials). Following one baseline trial $(0: 00 \mathrm{MIN})$, the tail was stimulated for $5 \sec (1: 35 M I N$, stippled bar). Twenty seconds following tail stimulation (test trial, 2:00 MIN), the LFS-A complex EPSP is reduced (dashed line indicates peak baseline response). The response recovers to baseline levels 2 min later (recovery trial, 4:00 MIN). $B$, Summary of experiments examining the time course of this form of inhibition. LFS-A responses were tested either immediately after, or 20,40 , or $60 \mathrm{sec}$ following tail stimulation. As a measure of the net motor neuron response in these and subsequent experiments, the area underneath the initial $500 \mathrm{msec}$ of the tap-evoked EPSP was integrated (see Materials and Methods). The data are normalized to their respective baseline measures, and are expressed as means \pm SEM. Significant inhibition was found at all test intervals. $\left({ }^{* *}, p<0.01 ;{ }^{*}, p\right.$ $<0.05$; compared to baseline). evoked action potentials in these cells were significantly reduced (mean diff. $=-3.3 \pm 0.9$ spikes, $t_{6}=-3.80, p<0.01$ ). The responses in recovery trials were still significantly different from baseline (mean diff. $=-1.1 \perp 0.4$ spikes, $t_{6}=-2.83, p<0.05$ ) but were significantly greater than test values (mean diff. $=2.1$ \pm 0.4 spikes, $t_{6}=-3.38, p<0.01$ ), indicating significant recovery. Thus these data show that weak tail input generates transient inhibition of siphon-evoked responses throughout the entire L29 interneuronal pool.

2. LFS motor neurons. Since L29 interneurons are a significant source of excitatory input to the LFS siphon motor neurons (Frost et al., 1988; Fischer and Carew, 1993a), we expected that the tail-induced inhibition of siphon-evoked L29 responses would be paralleled by a similar inhibition in siphon-evoked LFS-A responses. We examined this question in a separate series of experiments: a typical experiment is illustrated in Figure $7 \mathrm{~A}$. Twenty seconds following tail stimulation (shaded bar), the siphon-evoked complex EPSP in the motor neuron was noticeably reduced compared to the baseline response, in this case by $26 \%$. The evoked response recovercd toward bascline 2 min later. Similar results were obtained in additional experiments, which also examined the time course of tail-induced inhibition. These data, summarized in Figure $7 B$, parallel those obtained for L29-A neurons (Fig. 6B). Significant inhibition of the siphon-evoked complex EPSP was observed at all test intervals examined; it was greatest immediately following tail stimulation and progressively less at 20,40, and $60 \mathrm{sec}$ test intervals (immed: mean diff. $=-43 \pm 9 \%, t_{5}=4.95, p<0.01 ; 20 \mathrm{sec}$ : mean diff. $=$ $-31 \pm 4 \%, t_{5}=7.30, p<0.001 ; 40 \mathrm{sec}:$ mean diff. $=-19 \pm$ $3 \%, t_{9}=6.07, p<0.001 ; 60 \mathrm{sec}$ : mean diff. $=-22 \pm 6 \%, t_{8}=$ $3.68, p<0.01$ ). The complex EPSPs in the 2 min recovery trials for the immediate, 20 , and $60 \mathrm{sec}$ tests were not significantly different from baseline (immed: mean diff. $=-1 \pm 4 \%, t_{5}=$ $0.29, p=0.78 ; 20 \mathrm{sec}$ : mean diff. $=-11 \pm 6 \%, t_{5}=1.97, p=$ $0.11 ; 60 \mathrm{sec}$ : mean diff. $=-3 \pm 9 \%, t_{8}=0.31, p=0.76$ ).
Recovery measures for the $40 \mathrm{sec}$ test were still significantly different compared to baseline (mean diff. $=-10 \pm 3 \%, t_{9}=$ $3.64, p<0.01$ ); however, these measures were significantly greater than the test EPSPs (mcan diff. $=9 \pm 2 \%, t_{9}=4.14$, $p<0.01$ ), indicating significant recovery.

The above experiments show that weak tactile stimulation of the tail produces inhibition of siphon-evoked input to LFS-A siphon motor neurons. These observations left open the question of whether similar tail-induced inhibition would also be observed in the LFS-B motor neurons. We carried out an independent series of experiments $(N=5)$ to examine this question (data not shown). Because of the sustained activity onto LFS-B cells evoked by the tail stimulus (see Fig. $2 B$ ), we were not able to accurately measure the complex EPSP evoked by siphon-tap as was done for LFS-A cells. However, we were sometimes able to discern and measure the initial peak amplitude evoked by the siphon stimulus. Using this measure, we found that $20 \mathrm{sec}$ following tail stimulation the amplitude of the siphon-evoked response was significantly inhibited compared to baseline (mean diff. $=-26 \pm 10 \%, t_{4}-2.76, p<0.05$ ); as with the LFS-A cells, significant recovery was observed 2 min later (mean diff. $=-9 \pm 5 \%, t_{4}=-2.50, p=0.13$ ). These data show that weak tail stimulation induces inhibition of siphon-evoked input to both the LFS-A and LFS-B siphon motor neurons.

\section{Inactivation of L30 attenuates tail-induced inhibition}

Collectively, the experiments described thus far demonstrate that weak tail stimulation produces inhibition of siphon-evoked excitation in both I.29 excitatory interneurons and LFS motor neurons, with a similar time course of approximately $60 \mathrm{sec}$. Prime candidates for mediating this inhibitory process are the L30 inhibitory interneurons, which are strongly activated (Fig. 4A) and potentiated (Fig. 5) by weak tactile stimulation of the tail. Additionally, in previous work we showed that direct intracellular activation of a single $\mathrm{L} 30$ interneuron, at a rate and 
Figure 8. Inactivation of $\mathrm{L} 30$ interneurons attenuates tail stimulation-induced inhibition of siphon tap-evoked L29-A responses. L30 inactivation experiments were performed in two parts: PART 1. BASELINE INHIBITION, and PART 2. L3O INACTIVATION. The same L29-A interneuron is always examined in both parts. PART 1 . BASELINE INHIBITION trial, recording from an identified L29-A cell. Following one baseline trial $(0: 00 \mathrm{MIN})$, the tail was stimulated for $5 \mathrm{sec}$ (4:35, stippled bar). Tail stimulation-evoked responses of two identified L30 interneurons are shown in the inset. Twenty seconds following tail stimulation (test trial, 5:00), the number of L29-A spikes is reduced, from six spikes to three spikes. The response recovers to baseline levels $5 \mathrm{~min}$ later (recovery trial, 10:00). PART 2. L3O INACTIVATION trial: The same protocol as in Part 1 was used, except that the two L30 interneurons were hyperpolarized throughout the experiment (the responses of these L30 interneurons to the tail stimulation are shown in the inset). A smaller reduction in the L29-A response (from six to five spikes) is observed $20 \mathrm{sec}$ following tail stimulation (test trial, 5:00), compared to the BASELINE INHIBITION trial.
PART 1. BASELINE INHIBITION
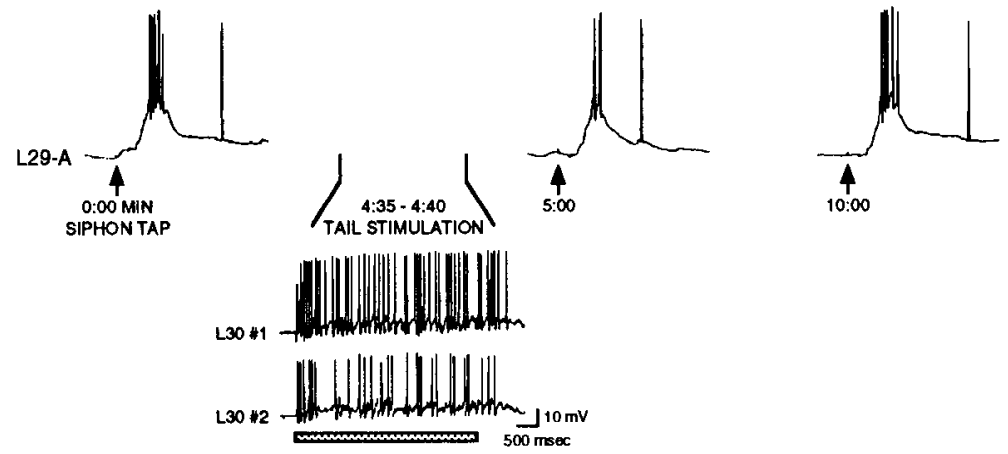

PART 2. L3O INACTIVATION
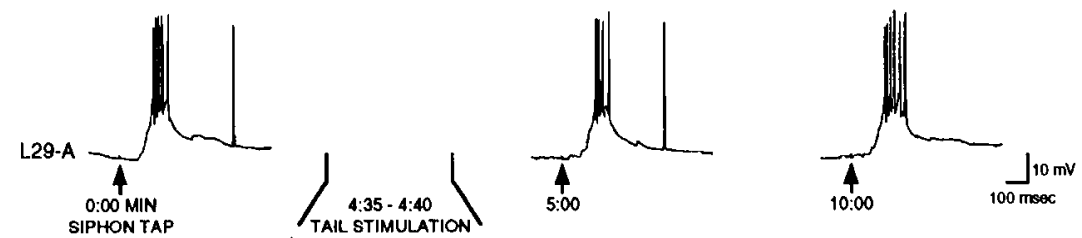

duration $(5 \mathrm{sec})$ similar to tail-induced activation, produced similar inhibition of siphon-evoked activation of both L29 interneurons and LFS motor neurons (Fischer and Carew, 1993a). The mechanism of the inhibition involved activity-dependent potentiation of the L30 IPSP; direct L30 activation for $5 \mathrm{sec}$ potentiated the L30 IPSP onto L29 for approximately $60 \mathrm{sec}$ (Fischer and Carew, 1993a), similar to the time course of inhibition produced by weak tail stimulation (Figs. $6 B, 7 B$ ).

To directly examine the role of the L30 interneurons, we inactivated them with intracellular hyperpolarization during weak stimulation of the tail. The protocol in these experiments was similar to that described above. L29-A interneurons and LFS-A motor neurons were examined in separate experiments. Input to the SWR was evoked by siphon tap at a $5 \mathrm{~min}$ ISI (the ISI was increased from previous experiments to diminish the possibility of response decrement). Three siphon stimuli were given: a baseline, a test, and a recovery stimulus. Prior to the test stimulus, the tail was stimulated as before for $5 \mathrm{sec}$ (see Materials and Methods); the test stimulus was then given $20 \mathrm{sec}$ following the cessation of tail stimulation. Each experiment was performed in two parts. In Part 1 (Baseline Inhibition), the magnitude of tail-stimulus induced inhibition was assessed. In Part 2 (L30 Inactivation), two identified L30 interneurons (out of three; Hawkins et al., 198 1a) were hyperpolarized. Since L30 interneurons tended to fire upon release from hyperpolarization, they were kept hyperpolarized throughout Part 2 of the experiment, including during the siphon test stimulus (tap). Generally, L30 interneurons were not impaled until Part 2 of the experiment. Thus, the interval between Parts 1 and 2 was variable, ranging from 5 to $60 \mathrm{~min}$ (average $=17 \mathrm{~min}$ ). Only experiments in which both Parts 1 and 2 were completed were analyzed, permitting a direct comparison between Baseline Inhibition and L30 Inactivation trials in the same experiment.
Figure 8 illustrates a typical experiment examining L29-A neurons. Part 1 (Baseline Inhibition) demonstrates, as before, that weak tail stimulation reduces the number of L29-A spikes (from six to three spikes); recovery to baseline levels (six spikes) was observed $5 \mathrm{~min}$ later. In this example, the responses of two L30 neurons were recorded, illustrating that they fire continuously throughout the tail stimulation (shaded bar). Part 2 illustrates the same cells, this time with the two L30s hyperpolarized throughout the experiment. The baseline response of six spikes is the same as observed in Part 1. Following tail stimulation, tail-induced inhibition is attenuated: five spikes are now evoked in the L29-A cell. The response returns to baseline levels (six spikes) 5 min later.

A summary of nine experiments is shown in Figure 9. Baseline Inhibition (Part 1) data replicates previous experiments and demonstrates that tail stimulation produces significant inhibition of siphon-evoked L29-A responses (mean diff. $=-2.7 \pm$ 0.4 spikes, $t_{8}=6.53, p<0.01$ ), with significant recovery observed 5 min later (mean diff. $=-0.3 \pm 0.4$ spikes, $t_{8}=0.89$, $p=0.40$ ). In the corresponding L30 inactivation trials (Part 2), a significant reduction in tap-evoked L29-A responses was still observed (mean diff. $=-1.6 \pm 0.3$ spikes, $t_{8}=6.20, p<0.01$ ), again with significant recovery 5 min later (mean diff. $=0.4 \pm$ 0.2 spikes, $t_{8}=0.55, p=0.59$ ). However, as shown in Figure 9 , a direct comparison between the two types of test trials reveals that the inhibition produced in the baseline condition (Part 1) is significantly greater than that produced in L30 inactivation trials (Part 2) (mean diff. $=-1.1 \pm 0.3$ spikes, $t_{8}=-3.59, p$ $<0.01$ ). No significant difference was observed in the two conditions betwecn cither the baseline trials (mean diff. $-0.1 \pm$ 0.2 spikes, $t_{8}=0.55, p=0.59$ ) or recovery trials (mean diff. $=$ $-0.7 \pm 0.4$ spikes, $t_{8}=-1.79, p=0.11$ ). These results thus demonstrate that inactivation of only two L30 interneurons 
significantly attenuates the inhibition of tap-evoked L29-A responses produced by weak tail stimulation.

Data obtained from experiments examining LFS-A motor neurons parallel those described above for L29-A cells, as shown in Figure 10. In Part 1 (Baseline Inhibition), confirming previous experiments, weak tail stimulation (shaded bar) produced clear inhibition of the siphon-evoked complex EPSP, with recovery to baseline levels observed $5 \mathrm{~min}$ later. In the corresponding L30 Inactivation trial (Part 2), tail stimulation produced a comparatively smaller reduction of the evoked response in the LFS-A motor neuron. A summary of eight experiments is shown in Figure 11. The results show that inactivation of two L30 interneurons significantly attenuates tail-induced inhibition of LFS-A motor neurons. In Baseline Inhibition (Part 1) trials, tail stimulation produced a significant reduction of siphon-evoked LFS-A complex EPSPs (mean diff. $=-51 \pm 9 \%, t_{7}=5.60, p<0.01$ ), with significant recovery observed 5 min later (mean diff. $=-4$ $\pm 6 \%, t_{7}=0.63, p=0.55$ ). In the corresponding $\mathrm{L} 30$ inactivation trials (Part 2), a significant reduction in tap-evoked LFS-A responses was still observed (mean diff. $=-28 \pm 8 \%, t_{7}=3.54$, $p<0.01$ ), again with significant recovery $5 \mathrm{~min}$ later (mean diff. $=-3 \pm 5 \%, t_{7}=0.68, p=0.52$ ). However, a direct comparison between test trials in Parts 1 and 2 reveals that the inhibition produced in Baseline Inhibition trials is significantly greater than that produced in L30 Inactivation trials (mean diff. $\left.=-22 \pm 9 \%, t_{7}=-2.64, p<0.05\right)$. No difference between the two conditions was observed for either the baseline trials $\left(t_{7}=\right.$ $1.63, p=0.15)$ or recovery trials $\left(t_{7}=-0.12, p=0.91\right)$. Therefore, in addition to attenuating inhibition of L29 interneurons, L30 inactivation also significantly attenuates tail-induced inhibition of siphon-cvoked motor ncuron responscs.

Three potential sources of error in the above experiments should be directly addressed. First, since the L30 Inactivation trials followed the Baseline Inhibition trials, it is possible that the attenuated inhibition observed during the L30 Inactivation trials could be due, in part, to the fact that the inhibitory process had simply diminished over time. The data obtained in experiments examining the time course of tail stimulation-induced inhibition of L29 and LFS responses (Figs. 6, 7) help to rule out this possibility, since the same cells were often examined at different test intervals with no apparent diminution of inducible inhibition. Repeated, stable potentiation of the L30 IPSP was also observed in our earlier experiments (Fischer and Carew, 1993a). Second, since the L29 and L30 interneurons are electrically coupled (Hawkins et al., 1981a; Fischer and Carew, 1993a), it is possible that hyperpolarization of L30 led to a decrease in the firing of L29 neurons through passive current spread. This is unlikely to have significantly influenced our results, since we observed no decrement of baseline L29 responses in the L30 Inactivation trials (see Discussion), and the main effect following tail stimulation with two L30s hyperpolarized was a relative increase in the number of $L 29$ spikes.

A third possible source of error could arise if the tail was stimulated more vigorously in the Baseline Inhibition trials than in L30 Inactivation trials. To control for this possibility in each experiment we measured the area underneath the tail-evoked response in both the L29-A and LFS-A cells during the entire $5 \mathrm{sec}$ period of tail stimulation. For both series of experiments, there was no significant difference in tail-induced activation comparing Baseline Inhibition trials to L30 Inactivation trials (L29-A experiments: $t_{8}=0.48, p=0.64$; LFS-A experiments: $t_{7}=-0.57, p=0.59$ ), indicating that the significant reduction

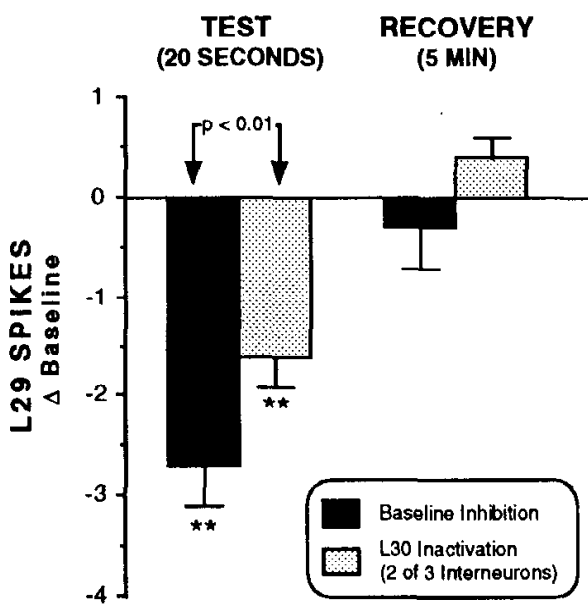

Figure 9. Summary of experiments examining the effects of L30 inactivation on tail stimulation-induced inhibition of $L 29$ responses. Direct comparison between Baseline Inhibition (solid bars) and L30 Inactivatior (stippled bars) trials; experiments as illustrated in Figure 8. The data are expressed as the mean difference score \pm SEM from their respective baseline measures. A significant difference is observed between Baseline Inhibition and L30 Inactivation trials at the $20 \mathrm{sec} T E S T$ trial, illustrating that inactivation of two (of three) L 30 interneurons significantly attenuates the tail stimulation-induced inhibition. $\left({ }^{* *}, p<\right.$ 0.01 ; compared to their respective baseline measures).

of inhibition we observe during L30 Inactivation trials compared to Baseline Inhibition trials is not due to a difference in tail stimulation per se. Since no attempt was made to precisely regulate tail stimulus intensity, our data do not allow us to determine whether L30 inactivation may have led to any quantifiable difference in the activity of L29 or LFS neurons evoked by tail stimulation. Such a difference may have important functional consequences. For example, since L29 neurons can act as facilitatory modulators in the SWR circuit (Hawkins et al., $1981 b$ ), any increase in their evoked firing could bias the SWR circuit towards facilitation. Thus, it will be of interest lo examine this general question under conditions of controlled tactile stimulation

\section{Discussion}

\section{Inhibition in the SWR circuit}

Recent studies in Aplysia have illustrated a potential role for inhibition in sensitization of siphon withdrawal responses produced by strong electrical shock to the tail (Krontiris-Litowitz et al., 1987; Mackey et al., 1987; Frost et al., 1988; Marcus et al., 1988; Rankin and Carew, 1989; Wright et al., 1991; Trudeau and Castellucci, 1993; Illich et al., 1994). In addition to this form of inhibition, the results of the present study illustrate that weak (non-noxious) tactile stimulation of the tail also produces inhibition within the SWR circuit. We characterized this form of inhibition by examining the effect of mild tail stimulation upon siphon tap-evoked responses in LFS siphon motor neurons and in L29 excitatory interneurons. For both cell types, weak tactile stimulation of the tail (for 5 sec) caused a significant decrease in their evoked synaptic response to siphon tap. This inhibition was transient, having a time course of approximately $60 \mathrm{sec}$. Additionally, we have recently found that weak tail stimulation produces a similar inhibition of the SWR in intact, freely moving animals (Blazis et al., 1994). Thus, both weak and strong stimulation of the tail can produce inhibition within 
Figure 10. Inactivation of L30 interneurons attenuates tail stimulation-induced inhibition of siphon-evoked complex EPSPs in LFS motor neurons. L30 inactivation experiments were performed in two parts: $P A R T$ 1. BASELINE INHIBITION, and PART 2. L3O INACTIVATION. The same motor neuron is always examined in both parts. PART 1. BASELINE INHIBITION trial, recording from an identified LFS-A cell. Following one baseline trial $10: 00$ $M I N$ ), the tail was stimulated for $5 \mathrm{sec}$ (4:35, stippled bar). Twenty seconds following tail stimulation (test trial, 5:00), the LFS-A complex EPSP is reduced (dashed line indicates peak baseline response). The response recovers to baseline levels $5 \mathrm{~min}$ later (recovery trial, 10:00). PART 2. L30 INACTIVATION trial, following the same protocol as Part 1 , except that the two L30 interneurons were hyperpolarized throughout the experiment (the responses of these L30 interneurons to the tail stimulation are shown in the inset). A smaller reduction in the LFS-A response is observed 20 sec following tail stimulation (test trial, 5:00), compared to the BASELINE INHIBITION trial.
PART 1. BASELINE INHIBITION

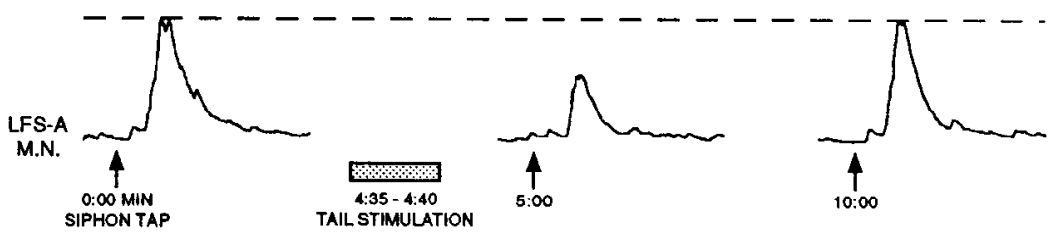

PART 2. L3O INACTIVATION

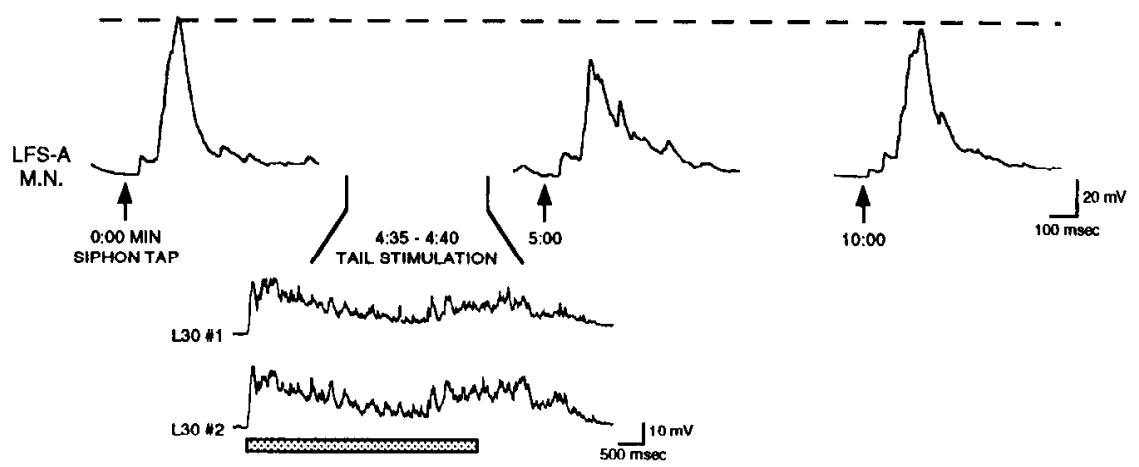

the SWR circuit, illustrating that inhibitory processes can be activated in this system by a wide range of environmental stimuli.

In our analysis of tail stimulation-induced inhibition, we examined subtypes of the LFS motor neurons and L29 interneurons (see Figs. 2 and 3, and related text). The properties of these neuronal subtypes indicates the presence of distinct neural circuits that are differentially activated by stimulation of separate

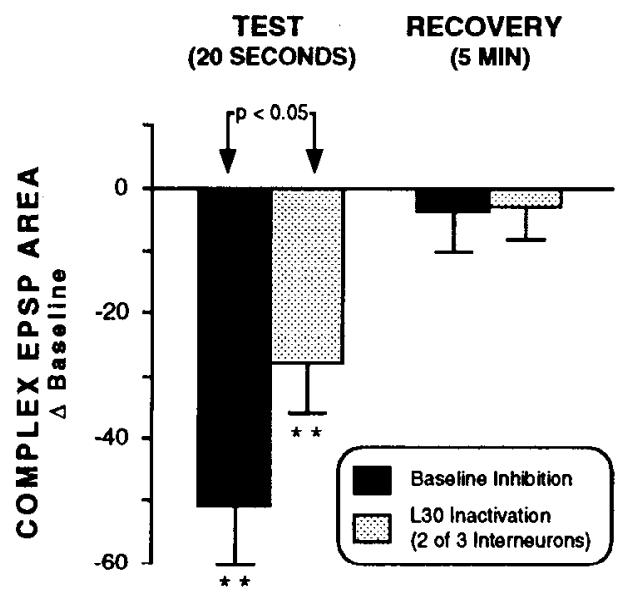

Figure 11. Summary of experiments examining the effects of L30 inactivation on tail stimulation-induced inhibition of complex EPSPs in LFS motor neurons. Direct comparison between Baseline Inhibition (solid bars) and L30 Inactivation (stippled bars) trials; experiments as illustrated in Figure 10. The data are normalized to their respective baseline measures, and are expressed as means \pm SEM. A significant difference is observed between Baseline Inhibition and L30 Inactivation trials at the $20 \mathrm{sec} T E S T$ trial, illustrating that inactivation of two (of three) L30 interneurons significantly attenuates the tail stimulationinduced inhibition. ${ }^{* *}, p<0.01$; compared to their respective basclinc measures). body regions. For example, in response to tail stimulation we observe a strong synaptic input onto the LFS-B cells which is not present in LFS-A cells. This synaptic input readily drives the LFS-B motor neurons, presumably by either overcoming or bypassing the tail-induced inhibition expressed within the SWR circuit. Since the LFS-B neurons receive strong excitatory synaptic input following tail stimulation, tail-induced inhibition of subsequent siphon-evoked input may appear of modest functional significance. However, general inhibition throughout the SWR circuit may help sharpen the LFS-B mediated tail directed response by reducing excitatory input onto other potentially competing motor neuron pools. Thus for siphon withdrawal evoked by tail stimulation, inhibition may play an important role in response selection by decreasing the relative amount of sensory information reaching potentially competing response systems. An analogous role for inhibition produced by noxious tail shock has recently been proposed by Illich et al. (1994). We do not yet know whether the inhibitory process we have identified interacts with other effector systems. However, further extension of our results may reveal a more general role for inhibition in coordinating and sharpening appropriate responses, both within and between effector systems.

\section{Neural mechanisms of inhibition in the SWR circuit}

There have been a number of studies investigating the cellular mechanisms of inhibition of the SWR produced by noxious tail stimulation; these studies have implicated several different candidate interneurons and neurotransmitter systems in mediating different aspects of this form of inhibition (Mackey et al., 1987; Wright and Carew, 1990; Fitzgerald and Carew, 1991; Wright et al., 1991; Buonomano et al., 1992; Small et al., 1992; Trudeau and Castellucci, 1993; Wright and Carew, 1994). In contrast, our results suggest that inhibition produced by weak tail stimulation is mediated largely by a single group of inhibitory interneurons, the L30s. These neurons exhibit several important 
characteristics which are consistent with their role in this low threshold form of inhibition. First, they exhibit robust responses to the weak tail stimuli used in our experiments. Second, the L30 IPSP onto the L29 interneurons demonstrates pronounced activity-dependent potentiation, either when $\mathrm{L} 30$ is activated directly (Fischer and Carew, 1993a), or by weak tail stimulation (Fig. 5). Third, the temporal dynamics of L30 IPSP potentiation (determined in Fischer and Carew, 1993a) parallels the time course of inhibition produced by weak tail stimulation. Finally, direct intracellular activation of a single L30 interneuron causes significant inhibition of siphon tap-evoked activation of both LFS motor neurons and L29 interneurons. The inhibition of motor neuron responses is largely due to L30 inhibition of the L29s, and possibly other excitatory interneurons such as the L34 class (Frost, 1987), since the L30 neurons do not directly inhibit the LFS motor neurons (Fischer and Carew, 1993a). It is relevant to note that since the probable mechanism of this inhibition is a potentiation of the L30 IPSP, the L30s must be coactivated with the excitatory interneurons to exert their inhibitory effect.

Based on these observations, we hypothesized that the inhibition of the SWR produccd by a weak tail stimulus is mediatcd by activating the L $30 \mathrm{~s}$, resulting in an increase in the strength of L30 inhibition onto L.29 (and possibly other) excitatory interneurons. We confirmed this hypothesis by showing that the inhibition produced by a weak tail stimulus was significantly attenuated when two (of three) L30 interneurons were inactivated (hyperpolarized) during tail stimulation, demonstrating that L30 activity is required for the inhibition. Even with two L30s inactivated, however, significant (albeit reduced) inhibition of siphon-evoked responses was still observed following tail stimulation. Interestingly, the amount of remaining inhibition (LFS cells: mean reduction in EPSP $=28 \%$; L29 cells: mean reduction in spikes $=1.6$ ) is very similar to that which we observed in previous experiments in which we activated a single L30 interneuron to produce inhibition (LFS cells: mean reduction in EPSP $=25 \%$; L29 cells: mean reduction in spikes = 1.9; Fischer and Carew, 1993a). Thus, it is possible that the remaining $\mathrm{L} 30$ interneuron we did not hyperpolarize could account for most if not all of the remaining inhibition, although the contribution of other neurons or mechanisms cannot be definitively ruled out.

It is interesting to note that L30 hyperpolarization did not affect baseline siphon tap-evoked responses in the L29 or LFS neurons. A possible explanation for this is that the L 30 interneurons are normally silent in the absence of tactile stimulation (Hawkins et al., 1981a; and unpublished observations), and the L30 IPSP prior to its potentiation by $\mathrm{L} 30$ activity is relatively small (Fischer and Carew, 1993a). Thus, in a condition such as our baseline trials where the $\mathrm{L} 30$ interneurons have not been previously active, elimination of L30-mediated inhibition (by hyperpolarization) would only remove a very modest amount of inhibition in the SWR circuit. This highlights a potential advantage of the transient, activity-dependent potentiation exhibited by the L30 interneurons: the strength of inhibition critically depends upon the recent tactile history of the animal. As described below, such a mechanism may have interesting and important adaptive consequences.

Although our data indicate that $\mathrm{L} 30$ has a major role in inhibition produced by weak tail stimulation, it probably plays no role in inhibition produced by noxious tail stimulation. We have repeatedly observed that $\mathrm{L} 30$ does not fire to strong tail shock, but in fact is inhibited (Fig. 4B). This suggests the existence of at least two inhibitory systems in the SWR circuit, which are independently responsive to weak or strong stimuli. Consistent with this notion is the observation that interneuron L16, which has a role in tail shock-induced inhibition (Wright and Carew, 1990, 1994), fires robustly to noxious tail stimulation but not to weak tail stimuli (Wright and Carew, 1990, 1994; Fischer and Carew, unpublished observations). The inhibition of L30 that we observe following noxious tail stimulation is intriguing in light of the results of Frost et al. (1988), who demonstrated that, following pleural-abdominal connective shock (an analog of tail shock) the amplitude of the L30 IPSP is markedly reduced, likely through presynaptic inhibition. Recently, we have found that tail shock also profoundly affects the ability of the L30 synapse to exhibit activity-dependent potentiation (Fischer and Carew, 1994). The existence of parallel inhibitory systems in the SWR, each mediated by different interneuronal circuitry and activated by different kinds of stimuli, raises intriguing functional questions. For example, a tail shockinduced decrease in L30 mediated inhibition may increase the evoked firing rates of $\mathrm{L} 29$ interneurons. Since the $\mathrm{L} 29 \mathrm{~s}$ can also act as modulatory interneurons (Hawkins et al., 1981b), this may bias the SWR circuit towards facilitation. It will thus be of considerable interest to examine how interactions between these inhibitory systems may contribute to the behavioral alterations in the SWR produced by a wide range of modulatory stimuli.

\section{Functional role of inhibitory modulation}

Cellular events that alter the efficacy of inhibition in a neural circuit can have important consequences in adjusting the net evoked output of that network. For example, a deficit in inhibitory function is believed to be a major factor underlying the increased excitability in the hippocampus following kindling (see, for example, Sloviter, 1987; Milgram et al., 1991; Merlin and Wong, 1993). Similarly, in Aplysia, decreasing the efficacy of inhibition may be important for producing sensitization of the SWR (Frost et al., 1988; Trudeau and Castellucci, 1993). Our present results demonstrate that there is increased inhibition within the SWR network following weak tactile stimulation. How might this increased inhibition contribute to the functioning of the SWR circuit? In our experiments, the net effect of this enhanced inhibition is a reduction in siphon-evoked excitatory input to siphon motor neurons, which decreases the likelihood that a siphon stimulus would produce a motor response. Under these conditions, the production of a response would require a stronger siphon stimulus to overcome the increased inhibition. In this fashion, the induced inhibition resulting from weak tactile stimulation can provide a mechanism for elevating the effective threshold of a motor neuron response based upon the recent tactile history of the animal. A larger signal (siphon input) would be required to produce a withdrawal response in an environment with higher levels of ambient tactile stimulation than in an environment with low ambient levels of tactile stimulation, in which inhibition would be reduced. Detection of a signal greater than background noise is a basic problem confronting all organisms: our results suggest a simple mechanism in the SWR in which inhibition evoked by ambient background stimuli can perform this task across a wide dynamic range.

There is evidence that such environmental modulation of the SWR occurs. Carew and Kupfermann (1974) demonstrated that animals living in a turbulent tide-pool environment showed 
reduced withdrawal responses to a siphon stimulus compared to animals living in a calm environment. Since a turbulent environment inherently contains a greater degree of ambient tactile stimulation, our results suggest that an important mechanism contributing to the decreased responsiveness of the SWR may be an activity-dependent increase in L30 mediated inhibition. It is interesting to note that the inhibition mediated by L30 wears off rather quickly (approximately $60 \mathrm{sec}$; Fischer and Carew, 1993a, and present observations), which could provide an effective mcchanism for restoring responsiveness in a environment that is suddenly reduced in ambient noise. Further, these temporal characteristics may help to distinguish this form of short-term inhibition, which may be involved in ongoing adaptation (gain control), from more long-lasting forms of modulation involving decreased responsiveness, such as long-term habituation (Carew et al., 1972; Carew and Kandel, 1973). To better understand these phenomena, it will be instructive to determine how long it takes the SWR to adjust to rapid changes in environmental conditions, and to examine how repetitive activation of $\mathrm{L} 30$, such as would occur in experiments examining long-term habituation, effects both short-term and longterm synaptic efficacy in L30. These and related experiments could provide valuable insights into the diverse roles inhibitory modulation can play in the adaptive functioning of a well-characterized neural circuit.

\section{References}

Blazis DEJ, Fischer TM, Carew TJ (1993) A neural network model of inhibitory information processing in Aplysia. Neural Comput 5:213227.

Blazis DEJ, Priver NJ, Fischer TM, Carew TJ (1994) Modulation of tail-induced inhibition of the siphon withdrawal reflex of Aplysia. Soc Neurosci Abstr 20: in press.

Buonomano DV, Cleary LJ, Byrne JH (1992) Inhibitory neuron produces heterosynaptic inhibition of the sensory-to-motor neuron synapse in Aplysia. Brain Res 577:147-150.

Byme JH (1987) Cellular analysis of associative conditioning. Physiol Rev 67:329-439.

Byrne JH, Zwartjes R, Homayouni R, Critz SD, Eskin A (1993) Roles of second messenger pathways in neuronal plasticity and in learning and memory. In: Advances in second messenger and phosphoprotein research (Shenolikar S, Nairn AC, eds), pp 47-108. New York: Raven.

Carew TJ, Kandel ER (1973) Acquisition and retention of long-term habituation in Aplysia: correlation of behavioral and cellular processes. Science 182:1158-1160.

Carew TJ, Kupfermann I (1974) The influence of different natural environments on habituation in Aplysia californica. Behav Biol 12: 339-345.

Carew TJ, Sahley CL (1986) Invertebrate learning and memory: from behavior to molecules. Annu Rev Neurosci 9:435-487.

Carew TJ, Pinsker HM, Kandel ER (1972) Long-term habituation of a defensive withdrawal reflex in Aplysia. Science 175:451-454.

Carew TJ, Walters ET, Kandel ER (1981) Classical conditioning in a simple defensive withdrawal reflex in Aplysia. J Neurosci 1:14261437.

Erickson MT, Walters ET (1988) Differential expression of psuedoconditioning and sensitization by siphon responses in Aplysia: novel response selection after training. J Neurosci 8:3000-3010.

Fang X, Clark GA (1990) Neural mechanisms of response specificity. I. Tail and mantle nerve shock produce differential effects on the siphon-withdrawal neuronal circuit in Aplysia. Soc Neurosci Abstr 16:596.

Fang X, Clark GA (1992) Neural mechanisms of response specificity. II. Cutaneous tail and mantle shock produce differential effects on the siphon-withdrawal neuronal circuit in Aplysia. Soc Neurosci Abstr 18:713.

Fang X, Clark GA (1993) Neural mechanisms of response specificity. III. Differential responses of siphon motor neurons and interneurons to tail and mantle stimulation in Aplysia. Soc Neurosci Abstr 19:813.
Fischer TM, Carew TJ (1993a) Activity dependent recurrent inhibition: A mechanism for dynamic gain control in the siphon withdrawal reflex of Aplysia. J Neurosci 13:1302-1314.

Fischer IM, Carew TJ (1993b) L30 interneurons mediate inhibition produced by a weak tail stimulus in the siphon withdrawal circuit of Aplysia. Soc Neurosci Abstr 19:17.

Fischer TM, Carew TJ (1994) Tail shock differentially modulates two forms of synaptic plasticity in inhibitory interneuron L30 of Aplysia. Soc Neurosci Abstr 20:in press.

Fitzgerald K, Carew TJ (1991) Serotonin mimics tail shock in producing transient inhibition in the siphon withdrawal reflex of Aplysia. J Neurosci 11:2510-2518.

Frost WN (1987) Mechanisms contributing to short- and long-term sensitization in Aplysia. PhD thesis, Columbia University.

Frust WN, Clark GA, Kandel ER (1988) Parallel processing of shortterm memory for sensitization in Aplysia. J Neurobiol 19:297-334.

Getting PA (1989) Emerging principles governing the operation of neural networks. Annu Rev Neurosci 12:185-204.

Harris-Warrick RM, Marder E (1991) Modulation of neural networks for behavior. Annu Rev Neurosci 14:39-57.

Hawkins RD, Schacher S (1989) Identified facilitator neurons L29 and L28 are excited by cutaneous stimuli used in dishabituation, sensitization, and classical conditioning of Aplysia. J Neurosci 9:42364245.

Hawkins RD, Castellucci VF, Kandel ER (1981a) Interneurons involved in mediation and modulation of gill-withdrawal reflex in $A p l y$ sia. I. Identification and characterization. J Neurophysiol 45:304314.

Hawkins RD, Castellucci VF, Kandel ER (1981b) Interneurons involved in mediation and modulation of gill-withdrawal reflex in Aplysia. II. Identified neurons produce heterosynaptic facilitation contributing to behavioral sensitization. J Neurophysiol 45:315-326.

Hawkins RD, Lalevic N, Clark GA, Kandel ER (1989) Classical conditioning of the Aplysia siphon-withdrawal reflex exhibits response specificity. Proc Natl Acad Sci USA 86:7620-7624.

Hawkins RD, Kandel ER, Siegelbaum SA (1993) Learning to modulate transmitter release: themes and variations in synaptic plasticity. Annu Rev Neurosci 16:625-665.

Hickie C, Walters ET (1990) Identified central motor neurons are necessary for directional siphon responses in Aplysia. Soc Neurosci Abstr 16:19.

Hickie C, Illich PA, Walters ET (1993) Motor neuronal correlates of siphon response inhibition and transformation in Aplysia. Soc Neurosci Abstr 19:578.

Illich PA, Joynes RL, Walters ET (1994) Response-specific inhibition during general facilitation of defensive responses in Aplysia. Behav Neurosci 108:614-623.

Kirkwood A, Bear MF (1994) Hebbian synapses in visual cortex. J Neurosci 14:1634-1645.

Korn H, Oda Y, Faber DS (1992) Long-term potentiation of inhibitory circuits and synapses in the central nervous system. Proc Natl Acad Sci USA 89:440-443.

Krontiris-Litowitz JK, Erikson MT, Walters ET (1987) Central suppression of defensive reflexes in Aplysia by noxious stimulation and by factors released from the body wall. Soc Neurosci Abstr 13:815.

Mackey SL, Glanzman DL, Small SA, Dyke AM, Kandel ER, Hawkins RD (1987) Tail shock produces inhibition as well as sensitization of the siphon withdrawal reflex of Aplysia: possible behavioral role for presynaptic inhibition mediated by the peptide Phe-Met-Arg-Phe$\mathrm{NH}_{2}$. Proc Natl Acad Sci USA 84:8730-8734.

Marcus EA, Nolen TG, Rankin CH, Carew TJ (1988) Behavioral dissociation of dishabituation, sensitization, and inhibition of Aplysia. Science 241:210-213.

Merlin ER, Wong RKS (1993) Synaptic modifications accompanying epileptogenesis in vitro-long-term depression of GABA-mediated inhibition. Brain Res 627:330-340.

Milgram NW, Yearwood T, Khurgel M, Ivy GO, Racine R (1991) Changes in inhibitory processes in the hippocampus following recurrent seizures induced by systemic administration of kainic acid. Brain Res 551:236-246.

Rankin CH, Carew TJ (1989) Devclopmental analysis in Aplysia reveals inhibitory as well as facilitatory effects of tail shock. Behav Neurosci 103:334-344.

Sloviter RS (1987) Decreased hippocampal inhibition and a selective loss of interneurons in experimental epilepsy. Science 235:73-76. 
Small SA, Cohen TE, Kandel ER, Hawkins RD (1992) Identified FMRFamide-immunoreactive neuron LPL16 in the left pleural ganglion of Aplysia produces presynaptic inhibition of siphon sensory neurons. J Neurosci 12:1616-1627.

Trudeau L-E, Castellucci VF (1992) Contribution of polysynaptic pathways in the mediation and plasticity of Aplysia gill and siphon withdrawal reflex: evidence for differential modulation. J Neurosci 12:3838-3848.

Trudeau L-E, Castellucci VF (1993) Functional uncoupling of inhibitory interneurons plays an important role in short-term sensitization of Aplysia gill and siphon withdrawal refiex. J Neurosci 13:21262135.

Walters ET (1989) Transformation of siphon responses during conditioning of Aplysia suggests a model of primitive stimulus-response association. Proc Natl Acad Sci USA 86:7616-7619.

Walters ET (1991) A functional, cellular, and evolutionary model of nocioceptive plasticity in Aplysia. Biol Bull 180:241-251.
Walters ET, Erickson MT (1986) Directional control and the functional organization of defensive responses in Aplysia. J Comp Physiol [A] 159:339-351.

Wright WG, Carew TJ (1990) Contribution of interneurons to tail shock induced inhibition of the siphon withdrawal reflex of Aplysia. Soc Neurosci Abstr 16:20.

Wright WG, Carew TJ (1994) A single identified interneuron gates tail shock-induced inhibition in the siphon withdrawal reflex of $A p l y$ sia. J Neurosci, in press.

Wright WG, Marcus EA, Carew TJ (1991) A cellular analysis of inhibition in the siphon withdrawal reflex of Aplysia. J Neurosci 11 : 2498-2509.

Wu WT, Lee SC, Krasne FB (1993) The mechanism of tonic inhibition of crayfish escape behavior: distal inhibition and its functional significance. J Neurosci 13:4379-4393. 